\title{
Early Fluorescence in situ Hybridization Assessment during Acute Myeloid Leukemia Induction Chemotherapy
}

\author{
Robert Schneidewend $^{a}$ Paul Hosking $^{b}$ Ruta Brazauskas $^{c}$ Jess Peterson $^{b}$ \\ Carlie Beaudin $^{\mathrm{a}}$ Laura Michaelis $^{\mathrm{a}}$ Ehab Atallah ${ }^{\mathrm{a}}$ Parameswaran Hari ${ }^{\mathrm{a}}$ \\ Karen Carlson ${ }^{\text {a, }} \mathrm{d}$ \\ ${ }^{a}$ Division of Hematology and Oncology and Department of Internal Medicine, The Medical College of Wisconsin, \\ Milwaukee, WI, USA; ${ }^{b}$ Division of Hematopathology and Department of Pathology, The Medical College of \\ Wisconsin, Milwaukee, WI, USA; ' ${ }^{C}$ ivision of Biostatistics and Institute for Health and Society, The Medical College of \\ Wisconsin, Milwaukee, WI, USA; ${ }^{d}$ The Blood Research Institute of Wisconsin, Milwaukee, WI, USA
}

The standard of care for upfront remission induction therapy for "fit" adults with de novo acute myeloid leukemia (AML) is continuous-infusion cytarabine with concurrent anthracycline (i.e., "7+3" regimen) [1]. Fourteen days after the initiation of chemotherapy, bone marrow is re-evaluated to identify patients who may benefit from immediate receipt of an additional cycle of remission induction chemotherapy. Current NCCN guidelines specify that a second cycle of induction chemotherapy should be administered prior to count recovery if (1) more than $5 \%$ of the cells in the day- 14 bone marrow sample are morphologically consistent with myeloblasts and (2) the clinical status of the patient permits safe administration of cytotoxic therapy [2].

Bone marrow cellularity on day 14 is often less than $10-20 \%$, limiting the absolute number of cells available for analysis and potentially changing the accuracy of morphologic blast estimation. Morphologic evaluation of aplastic bone marrow aspirates also lacks the precision to differentiate physiologic recovering myeloblasts from leukemic blasts, indicative of persistent disease. Between
46 and $77 \%$ of the patients with $>5 \%$ of bone marrow cells morphologically identified as myeloblasts on day- 14 marrow examination who do not receive additional chemotherapy still go on to achieve first complete remission (CR) from $7+3$ chemotherapy $[3,4]$. Thus, the limited potential to morphologically differentiate between physiologic and aberrant myeloblast populations in the day- 14 aspirate presents a prognostic dilemma [5].

Highly sensitive diagnostic methods for differentiating physiologic from leukemic myeloblasts are routinely applied to the diagnostic bone marrow examination. These include multiparameter flow cytometry (MFC), fluorescence in situ hybridization (FISH), real-time quantitative polymerase chain reaction, and next-generation sequencing [6], which have detection sensitivities of $10^{-4}$, $0.3-5 \%, 10^{-4}$ to $10^{-5}$, and $10^{-4}$ to $10^{-6}$, respectively [7]. Most commonly utilized among these is MFC, which can capture a majority of leukemia immunophenotypes and has shown to predict good response at day 14 [8]. However, MFC is limited by the variability in instrumentation between institutions [9-11].

\section{KARGER}

(c) 2018 S. Karger AG, Basel

E-Mail karger@karger.com

www.karger.com/aha
Karen Carlson

E-Mail kabarker@mcw.edu 
Table 1. Patient characteristics and bivariate analysis associated with achieving CR

\begin{tabular}{|c|c|c|c|}
\hline \multirow[b]{2}{*}{ Patient characteristics $(n=112)$} & \multicolumn{3}{|c|}{ Proportion of patients obtaining CR } \\
\hline & $\%$ & crude odds ratio $(95 \% \mathrm{CI})$ & $p$ value \\
\hline Age $($ median $=54$ years $)$ & n.a. & $0.95(0.92,0.99)$ & 0.02 \\
\hline \multicolumn{4}{|l|}{ Disease risk by ELN } \\
\hline Favorable, 20 (18) & 95 & Referent & 0.10 \\
\hline Intermediate, 44 (39) & 80 & $0.21(0.02,1.74)$ & \\
\hline Poor, $34(30)$ & 65 & $0.10(0.01,0.81)$ & \\
\hline Unknown, 14 (13) & 64 & $0.10(0.01,0.93)$ & \\
\hline Received additional chemotherapy & & & 0.05 \\
\hline No, $96(86)$ & 79 & Referent & \\
\hline Yes, $16(14)$ & 56 & $0.34(0.11,1.02)$ & \\
\hline Gender & & & 0.15 \\
\hline Female, 51 (46) & 82 & Referent & \\
\hline Male, $61(54)$ & 70 & $0.51(0.21,1.27)$ & \\
\hline Day-14 bone marrow morphologic blasts & & & $<0.01$ \\
\hline$<5 \%, 63(56)$ & 90 & Referent & \\
\hline$\geq 5 \%, 49(44)$ & 57 & $0.14(0.05,0.39)$ & \\
\hline \multicolumn{4}{|l|}{ FISH on day $14(n=50)$} \\
\hline Undetectable, 17 (34) & 94 & Referent & 0.06 \\
\hline Detectable, 33 (66) & 67 & $0.13(0.02,1.07)$ & \\
\hline
\end{tabular}

Values are $n(\%)$ unless otherwise indicated. CR, complete remission; ELN, European LeukemiaNet; FISH, fluorescence in situ hybridization.

FISH is readily available at most institutions and is frequently applied to the day-14 and remission bone marrow evaluations, if chromosomal abnormalities were identified on the diagnostic specimen. Conversion to a normal karyotype at the time of count recovery as measured by FISH correlates with positive long-term outcomes [12]. However, the prognostic implication of persistent FISH-detectable cytogenetic abnormalities in the day-14 marrow sample is unknown. We analyzed day-14 FISH results from 50 adult patients diagnosed with AML who had a diagnostic FISH abnormality treated at our institution and compared these results to treatment outcome.

\section{Chart Selection and Data Collection}

An Institutional Review Board-approved retrospective chart review was performed at the Medical College of Wisconsin to identify all adult patients diagnosed with AML from January 1, 2010, to March 15, 2015, who received standard-of-care induction chemotherapy defined as 7 days of continuous infusion of cytarabine (100-200 $\mathrm{mg} / \mathrm{m}^{2}$ per day) and 3 days of concurrent idarubicin (12 $\mathrm{mg} / \mathrm{m}^{2}$ per day) or daunorubicin $\left(60 \mathrm{mg} / \mathrm{m}^{2}\right.$ per day). Demographic information (age, gender) as well as leukemiaspecific information (European LeukemiaNet [ELN]) risk category [13], bone marrow cellularity, and morphologic myeloblast percentage from the time of diagnosis and the day-14 bone marrow biopsy were collected. Treatment information and response including administration of additional induction chemotherapy during aplasia and achievement of CR1 from the induction chemotherapy regimen were also recorded.

\section{FISH Analysis}

Dual-color, dual-fusion, deletion, break-apart, and locus-specific DNA probes that detect characteristic rearrangements and genetic abnormalities observed in AML (BCR-ABL1, PML-RARA, RUNX1T1-RUNX1, CBFB, monosomy 5/deletion 5q, and monosomy $7 /$ deletion $7 \mathrm{q}$ ) were applied to day-14 bone marrow aspirate specimens by FISH. Two-hundred unstimulated interphase cells were analyzed per probe, and the results were reported using the International System for Human Cytogenetic Nomenclature (ISCN 2009 and 2013). 
Table 2. AML patient characteristics by day-14 FISH results

\begin{tabular}{|c|c|c|c|}
\hline Patient characteristics & $\begin{array}{l}\text { Undetectable FISH } \\
\text { abnormalities on day-14 } \\
\text { bone marrow evaluation } \\
(n=17)\end{array}$ & $\begin{array}{l}\text { Detectable FISH } \\
\text { abnormalities on day- } 14 \\
\text { bone marrow evaluation } \\
(n=33)\end{array}$ & $p$ value \\
\hline Median age (range, years) & $54(23-73)$ & $56(20-72)$ & 0.69 \\
\hline Gender & & & 0.47 \\
\hline Female & $8(47)$ & $12(36)$ & \\
\hline Male & $9(53)$ & $21(64)$ & \\
\hline Disease risk & & & 0.01 \\
\hline Favorable & $5(29)$ & $5(15)$ & \\
\hline Intermediate & $9(53)$ & $5(15)$ & \\
\hline Poor & $3(18)$ & $21(64)$ & \\
\hline Unknown & 0 & $2(6)$ & \\
\hline \multicolumn{4}{|l|}{$<5 \%$ morphologic myeloblasts on } \\
\hline mid-cycle bone marrow evaluation & $14(82)$ & $12(36)$ & 0.002 \\
\hline Received additional chemotherapy & 0 & $24(73)$ & 0.02 \\
\hline Complete remission & $16(94)$ & $22(67)$ & 0.03 \\
\hline
\end{tabular}

Values are $n(\%)$ unless otherwise indicated. AML, acute myeloid leukemia; FISH, fluorescence in situ hybridization.

\section{Conventional Cytogenetics}

Chromosome analysis was performed on unstimulated cultures from bone marrow aspirates. Twenty metaphase cells (when available) were analyzed by 2 ASCPcertified cytogenetic technologists, and abnormalities were described using the International System for $\mathrm{Hu}$ man Cytogenomic Nomenclature (ISCN 2016)

\section{Statistical Analysis}

First, the likelihood of achieving CR among different groups of patients was examined. A second analysis was performed on those patients who had cytogenetic abnormalities detected by FISH at the time of diagnosis. These patients were divided into 2 groups based on their day-14 bone marrow findings: those whose diagnostic cytogenetic abnormality was no longer detectable by FISH (i.e., FISH negative) and those who retained cells with the cytogenetic abnormality as detected by FISH.

Patient/disease-related factors were compared between the groups by using the Wilcoxon rank-sum test for continuous variables (age) and the $\chi^{2}$ test for categorical variables. Bivariate analyses were performed to examine factors associated with achieving a CR. A statistical significance of alpha $=0.05$ was used throughout, and
SAS OnDemand, version 9.4 (SAS Institute, Cary, NC), was used for all analyses.

Patient characteristics and odds of achieving CR are described in Table 1 and are consistent with the published literature [1]. The relapse-free survival for those achieving CR with the first induction therapy was $58 \%$, and the overall survival at the last noted clinical encounter for the entire cohort was $42 \%$. Older age and $\geq 5 \%$ myeloblasts detected by morphology on mid-cycle bone marrow evaluation were associated with lower odds of achievement of subsequent $\mathrm{CR}(\mathrm{OR}=0.952,95 \% \mathrm{CI}[0.915,0.991]$; $\mathrm{OR}=$ $0.140,95 \%$ CI [0.051, 0.387], respectively). There were no significant differences in CR rates observed between ELN disease risk subgroups [13] or by gender.

Fifty patients had detectable FISH abnormalities in their leukemic blasts at diagnosis. Seventeen (34\%) converted to FISH negative by the mid-cycle bone marrow evaluation, and 33 (64\%) retained FISH-detectable abnormalities (Table 2). Patients whose mid-cycle bone marrow sample was FISH negative for AML-related abnormalities were more likely to (1) have no morphologically detectable myeloblasts ( 82 vs. $36 \%, p=0.002$ ) and (2) obtain a subsequent CR ( 94 vs. $67 \%, p=0.031$ ) compared with those in whom day-14 FISH was with persistent AML-related abnormalities. As expected, individuals with a favorable and intermediate risk of AML were more likely to have converted to FISH negativity on mid-cycle 
evaluation compared to those with poor risk $(p=0.005)$ (Table 2).

Of the 12 patients with FISH-positive disease but $<5 \%$ blasts morphologically on mid-cycle evaluation, 7 (58\%) obtained a CR without additional chemotherapy, 3 received reinduction and obtained a CR, 1 received reinduction but had refractory disease, and 1 was considered having refractory disease/induction failure in the absence of further chemotherapy administration. Chromosomal abnormalities for the 7 who obtained a CR without additional chemotherapy are as follows: $\mathrm{t}(8 ; 21) ; \mathrm{t}(11 ; 17) ;+8$, idem, +i(5); +8, +9; der(16)inv(16)t(4;16); inv(16); +8, $\operatorname{inv}(16)$; and $\operatorname{add}(\mathrm{X}),+8$. The 3 who received additional chemotherapy did so based on subsequent biopsies performed during a period of prolonged count recovery. Conventional cytogenetic (CC) analysis was attempted on 29 of the day-14 biopsy samples. Of those, 7 were failures due to insufficient cell growth or metaphase chromosomes, 9 were karyotyped as normal, and 13 were positive. Three were positive by FISH and negative by CC; one was negative by FISH and positive by CC; 18 had concordant results (both positive or both negative); 4 were positive by FISH and failed to grow or generate sufficient metaphase chromosomes, and 3 were FISH negative and failed to grow or generate sufficient metaphase chromosomes.

This study demonstrates that conversion from FISH positive to FISH negative by the day- 14 postinduction bone marrow evaluation strongly correlated with higher CR rates from standard AML induction chemotherapy in our patient population. However, the significance of the persistence of these chromosomal rearrangements at day 14 is less clear. While $40 \%$ of the patients with AML will not have cytogenetic abnormalities that can be detected by standard FISH probes, the remaining $60 \%$ do [14]. We conclude that normalization of FISH-detectable abnormalities at the mid-cycle bone marrow evaluation is potentially prognostic and merits a prospective study to validate these findings in a larger multi-institutional cohort. Although less routinely available, application of additional genetic evaluation techniques such as next-generation sequencing for mid-point bone marrow evaluation may similarly correlate with treatment outcome and should be considered for prospective examination.

\section{Acknowledgements}

The work was in part supported by the Medical College of Wisconsin Department of Internal Medicine, Division of Hematology and Oncology fellowship program (R.S.) and start-up funds (K.C.). K.C. is also supported by the NIH/NHLBI 5K08HL127187 and the Froedtert Foundation's Aplastic Anemia Cancer Research Fund.

\section{Disclosure Statement}

The authors declare that there are no conflicts of interest to disclose.

\section{Author Contributions}

R.S., K.C., and P. Hosking conceptualized this retrospective review, and R.S., K.C., C.B., and P. Hosking completed the data collection. R.S. and R.B. performed the statistical analysis. K.C., R.S., C.B., P. Hari, J.P., E.A., and L.M. participated in the clinical care of the patients, and R.S. and K.C. wrote the manuscript that was reviewed, edited, and agreed upon by all authors.

\section{References}

- 1 Fernandez HF, Sun Z, Yao X, Litzow MR, Luger SM, Paietta EM, Racevskis J, Dewald GW, Ketterling RP, Bennett JM, Rowe JM, Lazarus HM, Tallman MS: Anthracycline dose intensification in acute myeloid leukemia. N Engl J Med 2009;361:1249-1259.

2 O'Donnell MR, Tallman MS, Abboud CN, Altman JK, Appelbaum FR, Arber DA, Bhatt V, Bixby D, Blum W, Coutre SE, De Lima M, Fathi AT, Fiorella M, Foran JM, Gore SD, Hall AC, Kropf P, Lancet J, Maness LJ, Marcucci G, Martin MG, Moore JO, Olin R, Peker D, Pollyea DA, Pratz K, Ravandi F, Shami PJ, Stone RM, Strickland SA, Wang ES, Wieduwilt M, Gregory K, Ogba N: Acute myeloid leukemia, version 3.2017, NCCN clinical practice guidelines in oncology. J Natl Compr Canc Netw 2017;15:926-957.

- 3 Yanada M, Borthakur G, Ravandi F, BuesoRamos C, Kantariian H, Estey E: Kinetics of bone marrow blasts during induction and achievement of complete remission in acute myeloid leukemia. Haematologica 2008;93: 1263-1265.

4 Yezefski T, Xie H, Walter R, Pagel J, Becker PS, Hendrie P, Sandhu V, Shannon-Dorcy K, Abkowitz J, Appelbaum FR, Estey E: Value of routine "day 14" marrow exam in newly diagnosed AML. Leukemia 2015;29:247249.

5 Pullarkat V, Aldoss I: Prognostic and therapeutic implications of early treatment re- sponse assessment in acute myeloid leukemia. Crit Rev Oncol Hematol 2015;95:3845.

-6 Thol F, Kolking B, Damm F, Reinhardt K, Klusmann JH, Reinhardt D, von Neuhoff N, Brugman MH, Schlegelberger B, Suerbaum S, Krauter J, Ganser A, Heuser M: Next-generation sequencing for minimal residual disease monitoring in acute myeloid leukemia patients with FLT3-ITD or NPM1 mutations. Genes Chromosomes Cancer 2012;51:689695

7 Al-Mawali A, Gillis D, Lewis I: The role of multiparameter flow cytometry for detection of minimal residual disease in acute myeloid leukemia. Am J Clin Pathol 2009;131:16-26. 
8 Kohnke T, Sauter D, Ringel K, Hoster E, Laubender RP, Hubmann M, Bohlander SK, Kakadia PM, Schneider S, Dufour A, Sauerland MC, Berdel WE, Buchner T, Wormann B, Braess J, Hiddemann W, Spiekermann K, Subklewe M: Early assessment of minimal residual disease in AML by flow cytometry during aplasia identifies patients at increased risk of relapse. Leukemia 2015;29:377-386.

-9 Carlson KS, Guzman ML: Is minimal residual disease monitoring clinically relevant in adults with acute myelogenous leukemia? Curr Hematol Malig Rep 2013;8:109-115.

10 Chen X, Xie H, Wood BL, Walter RB, Pagel JM, Becker PS, Sandhu VK, Abkowitz JL, Appelbaum FR, Estey EH: Relation of clinical response and minimal residual disease and their prognostic impact on outcome in acute myeloid leukemia. J Clin Oncol 2015;33:12581264.
1 Wood BL: Principles of minimal residual disease detection for hematopoietic neoplasms by flow cytometry. Cytometry B Clin Cytom 2016;90:47-53.

12 Bacher U, Kern W, Schoch C, Schnittger S, Hiddemann W, Haferlach T: Evaluation of complete disease remission in acute myeloid leukemia: a prospective study based on cytomorphology, interphase fluorescence in situ hybridization, and immunophenotyping during follow-up in patients with acute myeloid leukemia. Cancer 2006;106:839-847.
13 Mrozek K, Marcucci G, Nicolet D, Maharry KS, Becker H, Whitman SP, Metzeler KH, Schwind S, Wu YZ, Kohlschmidt J, Pettenati MJ, Heerema NA, Block AW, Patil SR, Baer MR, Kolitz JE, Moore JO, Carroll AJ, Stone RM, Larson RA, Bloomfield CD: Prognostic significance of the European LeukemiaNet standardized system for reporting cytogenetic and molecular alterations in adults with acute myeloid leukemia. J Clin Oncol 2012;30: 4515-4523.

14 Grimwade D, Walker H, Oliver F, Wheatley K, Harrison C, Harrison G, Rees J, Hann I, Stevens R, Burnett A, Goldstone A: The importance of diagnostic cytogenetics on outcome in AML: analysis of 1,612 patients entered into the MRC AML 10 trial. The Medical Research Council Adult and Children's Leukaemia Working Parties. Blood 1998;92: 2322-2333. 